Associations between IQ and alcohol consumption in a population of young males A large database analysis

\author{
Journal Article \\ Author(s): \\ Müller, Mario; Kowalewski, R.; Metzler, S.; Stettbacher, A.; Rössler, Wulf; Vetter, S. \\ Publication date: \\ 2013-12-01 \\ Permanent link: \\ https://doi.org/10.3929/ethz-b-000078034 \\ Rights / license: \\ In Copyright - Non-Commercial Use Permitted \\ Originally published in: \\ Social Psychiatry and Psychiatric Epidemiology 48(12), https://doi.org/10.1007/s00127-013-0666-2
}




\title{
Associations between IQ and alcohol consumption in a population of young males: a large database analysis
}

\author{
Mario Müller • R. Kowalewski • S. Metzler • \\ A. Stettbacher $\cdot$ W. Rössler $\cdot$ S. Vetter
}

Received: 2 July 2012/ Accepted: 7 February 2013/Published online: 27 February 2013

(C) Springer-Verlag Berlin Heidelberg 2013

\begin{abstract}
Purpose This study aimed at exploring the relationship between intelligence quotient (IQ) and alcohol consumption in a large sample of young males. This study explored whether IQ influences alcohol drinking and which pathways might be involved. We further hypothesized that IQ differences between lifetime abstainers and former drinkers exist, and that they primarily result from different group characteristics.

Method Within a psychiatric-epidemiological survey using a cross-sectional design IQ-tests were administered to approximately 50,000 Swiss conscripts at age of about 20 years. The sample was divided into four alcohol consumption categories (rare, occasional, moderate and daily drinking) and two non-drinker categories (former drinking and lifetime abstinence). Probabilities for different levels of consumption or former drinking against lifetime abstention in relation to IQ were estimated using multinomial logistic regression. Models were adjusted for education, disability pension, tobacco/cannabis use, migration, parental alcohol disorders, and mental health.
\end{abstract}

M. Müller $(\bowtie) \cdot$ S. Vetter

Centre for Disaster and Military Psychiatry,

University of Zurich, Militärstrasse 8, 8021 Zurich, Switzerland

e-mail: mario.mueller@access.uzh.ch

M. Müller · R. Kowalewski · S. Metzler · W. Rössler ·

S. Vetter

Department of Psychiatry, Psychotherapy and Psychosomatics,

Zurich University Hospital for Psychiatry, Zurich, Switzerland

\section{A. Stettbacher}

Medical Services of the Swiss Armed Forces, Bern, Switzerland

W. Rössler

Collegium Helveticum, University of Zurich and Swiss Federal

Institute of Technology, Zurich, Switzerland
Results After adjusting for confounders full-scale IQ displayed positive associations with being a rare (OR 1.13; CI $95 \%$ 1.07-1.19), occasional (OR 1.41; CI $95 \%$ 1.33-1.48), and moderate drinker (OR 1.53; CI $95 \%$ 1.45-1.62), and negative associations with being a former drinker (OR 0.85; CI 95 \% 0.79-0.93). Daily drinking was positively associated only with the performance subscale IQ (OR 1.12; CI $95 \%$ 1.02-1.22). Confounders contributed significantly to the IQ-alcohol association and, therefore, highlight the distinction of non-drinkers into lifetime abstainers and former drinkers.

Conclusions Our data confirmed the positive link between IQ and moderate drinking. Lower IQ in nondrinkers, however, seems to be related to earlier consumption and the presence of other risk factors.

Keywords IQ · Alcohol consumption · Alcohol abstainers · Confounders · Full population survey

\section{Introduction}

There is a vast body of evidence supporting a link between alcohol consumption and cognitive ability [1]. This association does not, however, necessarily follow a simple doseresponse pattern since particular drinking behaviors were positively related to cognitive performance while others were not-low-to-moderate drinkers tend to have a comparably higher intelligence quotient (IQ) [2-5]. Although this link can largely be attributed to confounding variables, e.g., psychosocial problems and other related risk factors, which are overrepresented in heavy drinkers and most abstainers [6, 7], its interpretation is hampered by the question of reverse causality. Most studies relating alcohol consumption to cognitive ability in later life revealed some evidence for an 
IQ-lowering effect of heavy consumption (and abstinence) over time, whereas moderate drinking was associated with absent or reduced risk for dementia and cognitive impairment [8-10]. However, when adjusted for early childhood IQ these associations were no longer so apparent $[11,12]$. This suggests that a particular drinking behavior might be affected by earlier cognitive ability rather than the reverse [1, 13]. Follow-up studies based on IQ assessments in childhood or at military conscription revealed strong links to subsequent drinking patterns and later alcohol-type preferences [11, 14, 15]. A possible reason for this non-linear relationship between intelligence and alcohol consumption might be that intelligence plays an important role in certain lifestyle choices which are in turn related to specific drinking behaviors [1]. Furthermore, alcohol consumption is considered to be a maladaptive coping strategy, which may also reflect lower cognitive abilities [16, 17]. It can be assumed that in younger age groups, such as conscript samples, any deficits must have existed "before their cognitive functioning could have been affected by their drinking habits" [18]. Unfortunately, most studies considered non-drinkers as abstainers, regardless of prior drinking behavior [18]. Alcohol cessation is often linked to psychosocial problems [19] while those who never drank tend to abstain for ideological (e.g., cultural or religious) or other reasons [20-23]. Neglecting these differences may produce a significant bias favoring moderate drinkers [24]. Lower cognitive test scores in abstainers might reflect particular subgroups and is therefore an artifact of this unobserved heterogeneity [25]. This possibility has to our knowledge, not been considered in previous studies in cognitive research.

The purpose of this study was to examine the association between IQ test score, measured once at ages 18-22, and alcohol drinking behavior in a population-based sample of 49,444 young Swiss males. We hypothesize that IQ is negatively associated with non- and daily drinking and positively associated with rare to moderate drinking. Furthermore, we distinguished between lifetime abstainers and those who used to drink, i.e., former drinkers. Non-drinkers were, therefore, split into these two subgroups. We hypothesize that lower cognitive test results are not related to alcohol abstinence per se but rather to former drinking which, in turn may, be explained by confounding factors. These factors are assumed to be more specific for former drinkers and potentially to explain these differences in multivariate analysis.

\section{Methods}

Sample

Swiss males between 18 and 22 years of age are obliged to undergo military conscription regardless of whether they will eventually serve in the Armed Forces. The examination of physical and mental fitness includes a psychiatric screening questionnaire and cognitive ability tests. The present study uses data collected on Swiss Armed Forces conscripts in 2005 and 2006. Of the 51,555 males who completed the psychiatric screening questionnaire, 352 were excluded from analyses due to missing intelligence test data and a further 497 due to missing or inconsistent responses on alcohol use questions. One hundred and sixtytwo were dropped from analysis due to suspected simulation according to ICD-10 (Code Z76.5) during subsequent psychiatric examination. Those conscripts who received an ICD-10 diagnosis of organic mental disorders (Code F00F09; $N=16$ ) or mental retardation (Code F70-F79; $N=451)$ were also excluded, as these conditions are likely to affect cognitive functioning. Forty-nine thousand four hundred forty-four subjects (mean age $=19.71$ years, $\mathrm{SD}=1.01)$ were left in the dataset and used for analyses. This project of the Medical Department of the Swiss Armed Forces was undertaken in collaboration with the Centre for Disaster and Military Psychiatry at the University of Zurich. It was approved by the Zurich State Ethical Committee (KEK) as fulfilling all legal and data privacy protection requirements. All screening and test sessions were introduced and supervised by military test psychologists.

\section{Alcohol consumption}

Self-reported information about the frequency of alcohol consumption was split into five categories: "non-drinking", "rare drinking (1-5 times/year)", "occasional drinking (1-5 times/month)", "moderate drinking (1-5 times/week)", and "daily drinking". Additionally, conscripts were asked whether they have ever consumed alcohol. Based on this information the subsample of abstainers was split into lifetime abstainers and former drinkers. Table 1 displays prevalence rates of the specified categories of alcohol consumption used in this study.

IQ assessment

Full-scale (FSIQ), verbal (VIQ), and performance IQ (PIQ) were obtained for each subject using the intelligence test 95 (T95; [26, 27]). Two time-limited IQ subtests assessed verbal (synonym and vocabulary abilities) and performance ability (recognition abilities) with 30 items each. Both subscales have been thoroughly validated [27], revealing that the VIQ correlated highly with the verbal subscale ( $r=0.68)$ of the Wilde Intelligence Test (WIT; [28]) and the PIQ was highly correlated with the Form Board Test ( $r=0.52$ ) of the Kit of Factor-Referenced Cognitive Test (KIT; [29]). Full scores range from 0 to 60 and subtest scores range from 0 to 30 . The test scores have been 


\begin{tabular}{|c|c|c|c|c|c|c|c|c|c|c|c|}
\hline$\stackrel{\vec{Q}}{\vec{Q}}$ & $\begin{array}{l}\overline{0} \\
\dot{\vec{\nabla}}\end{array}$ & 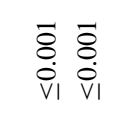 & $\begin{array}{l}\overline{8} \\
\dot{\mathrm{v}} \\
\end{array}$ & & $\begin{array}{l}\vec{\delta} \\
\dot{\vec{v}}\end{array}$ & $\begin{array}{l}\overline{8} \\
\stackrel{\overrightarrow{\mathrm{V}}}{1}\end{array}$ & $\begin{array}{l}\bar{\delta} \\
\dot{\vec{v}}\end{array}$ & $\begin{array}{l}\overline{8} \\
\stackrel{\dot{\mathrm{v}}}{1}\end{array}$ & & 8 & $\begin{array}{c}\bar{\delta} \\
\dot{\vec{v}}\end{array}$ \\
\hline 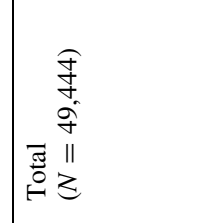 & $\begin{array}{l}8 \\
\dot{d} \\
+1 \\
+ \\
8 \\
\dot{8} \\
\dot{8}\end{array}$ & 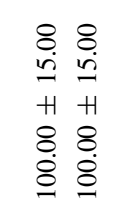 & 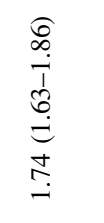 & 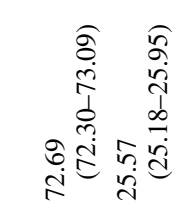 & 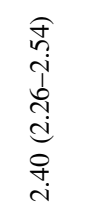 & 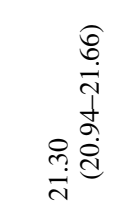 & 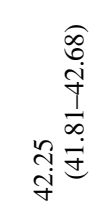 & 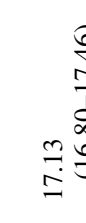 & & 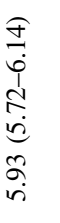 & $\begin{array}{l}\text { ơ } \\
0 \\
+1 \\
\text { के }\end{array}$ \\
\hline 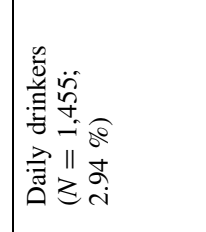 & 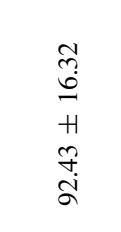 & 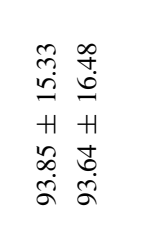 & $\begin{array}{l}\text { fr } \\
0 \\
0 \\
0 \\
0 \\
0 \\
0 \\
0 \\
0 \\
0\end{array}$ & 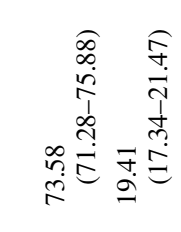 & 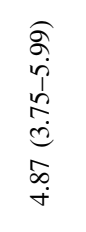 & 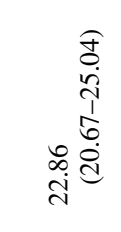 & 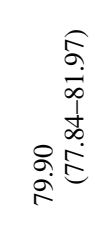 & कें & & 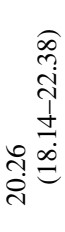 & $\begin{array}{l}\vec{\infty} \\
0 \\
+ \\
\ddot{0} \\
\dot{0}\end{array}$ \\
\hline 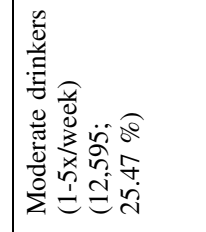 & 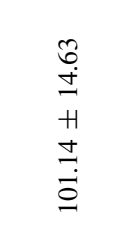 & 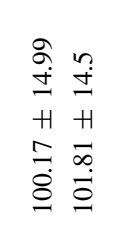 & 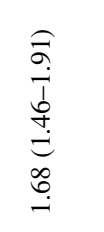 & 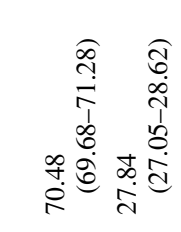 & 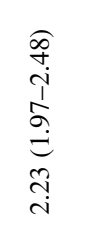 & 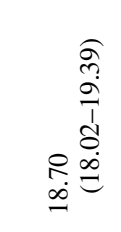 & 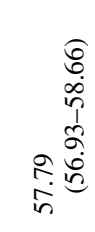 & 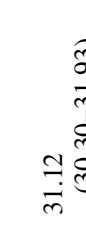 & & 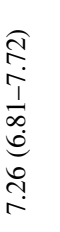 & $\begin{array}{l}0 \\
0 \\
0 \\
+1 \\
0 \\
0 \\
0\end{array}$ \\
\hline 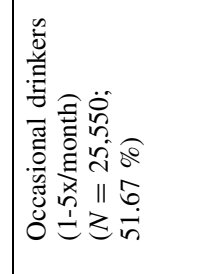 & $\begin{array}{l}\text { r } \\
\dot{I} \\
+1 \\
8 \\
8 \\
8 \\
8\end{array}$ & 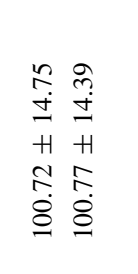 & 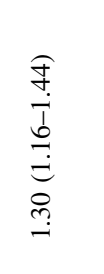 & 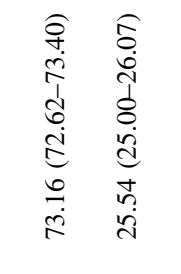 & 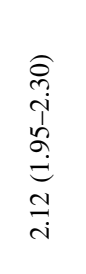 & 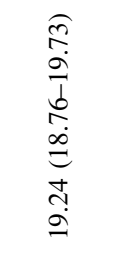 & 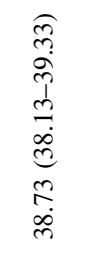 & 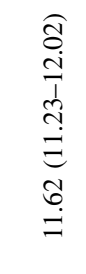 & & 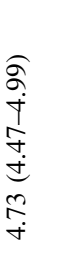 & $\begin{array}{l}\infty \\
0 \\
0 \\
+1 \\
0 \\
0 \\
0\end{array}$ \\
\hline $\begin{aligned} & 0 \\
& 0 \\
& 0 \\
& 0\end{aligned}$ & $\begin{array}{l}0 \\
2 \\
n \\
n \\
+1 \\
a \\
a \\
\vdots \\
a\end{array}$ & 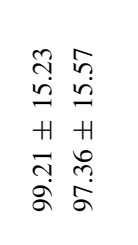 & 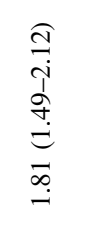 & 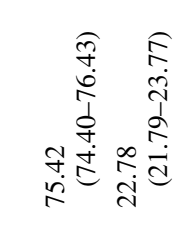 & 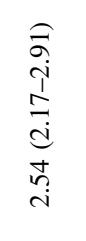 & 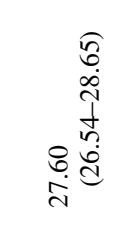 & 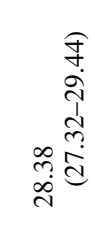 & $\begin{array}{l}\infty \\
\infty \\
\infty \\
0 \\
0 \\
0 \\
0 \\
0 \\
\infty \\
\infty\end{array}$ & & 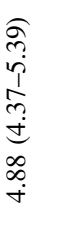 & $\begin{array}{l}\hat{3} \\
0 \\
+1 \\
0 \\
0 \\
0\end{array}$ \\
\hline 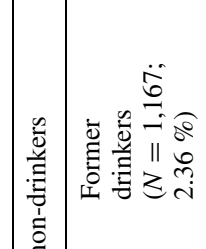 & 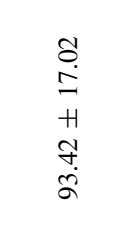 & 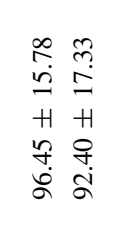 & 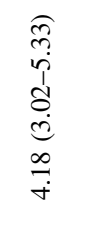 & 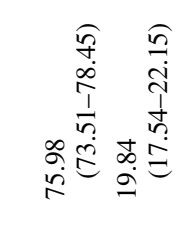 & 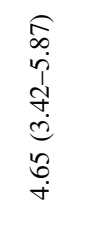 & 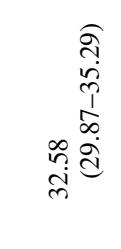 & 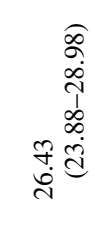 & 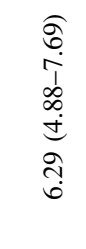 & & 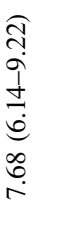 & 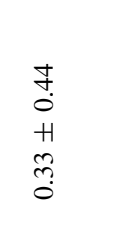 \\
\hline 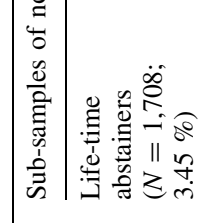 & $\begin{array}{l}0 \\
\stackrel{0}{0} \\
\stackrel{0}{+1} \\
\vec{n} \\
\overrightarrow{2} \\
\sigma\end{array}$ & 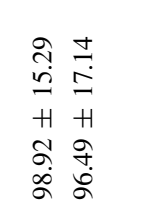 & 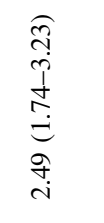 & 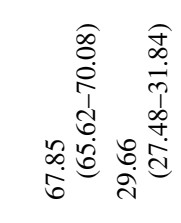 & 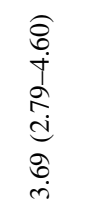 & 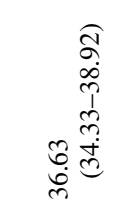 & 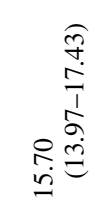 & 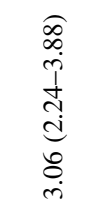 & & 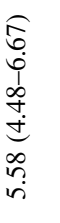 & $\begin{array}{l}0 \\
0 \\
0 \\
+1 \\
0 \\
0 \\
0\end{array}$ \\
\hline 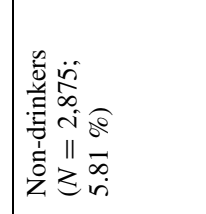 & $\begin{array}{l}\infty \\
0 \\
0 \\
+1 \\
0 \\
0 \\
\alpha\end{array}$ & 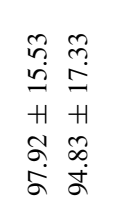 & 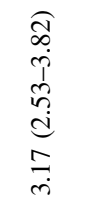 & 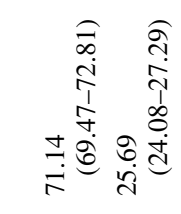 & $\begin{array}{l}\widehat{\sigma} \\
\dot{\infty} \\
\dot{w} \\
\infty \\
\infty \\
\infty \\
\infty \\
\infty \\
\dot{+}\end{array}$ & 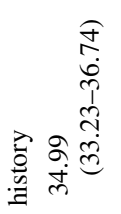 & 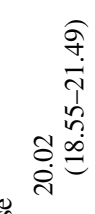 & 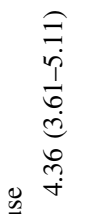 & & 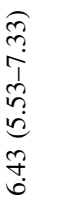 & $\begin{array}{l}0 \\
0 \\
0 \\
0 \\
+1 \\
0 \\
0 \\
0\end{array}$ \\
\hline
\end{tabular}


standardized for language of test (German, French, Italian), and converted to IQ-type scale scores (mean $=100$; $\mathrm{SD}=15)$.

\section{Related factors}

In order to account for other factors potentially related to alcohol consumption, information about selected sociodemographic, behavioral, and other specific risk factors was obtained.

Education as part of socioeconomic status was assessed using three categories: (a) Compulsory school not completed, (b) Basic education (secondary school or equivalent), and (c) Higher education (grammar school or equivalent and higher/tertiary). Education was then dichotomized (higher education versus lower) for final modeling. Information about current tobacco/cannabis use together with receipt of a disability pension was obtained. Response options were "yes" or "no".

Additionally, respondents were asked whether they know of any clinically diagnosed alcohol-related disorders (past or current) in either parent. Responses were collapsed to a single variable parental history of alcohol disorders (yes/ no). Finally, we asked whether either parent had immigrated to Switzerland (parental history of migration-yes/no).
Mental health was assessed using the SymptomChecklist-90-(R)evised (SCL-90-R; [30]), a well-validated and widely used clinical measure of psychopathology. In the current study, we used the SCL-90-R total score as a measure of general psychopathology.

Statistical analysis

Simple descriptive statistics are provided for the association between alcohol consumption and IQ/related factors (Table 1) together with distributions of IQ scores across the related factors (Table 2). To estimate the probability of a particular consumption category on the basis of IQ and other factors, separate multinomial logistic regression models for full and subscale IQ scores were calculated. Data were initially tested on the assumption of parallel regression since alcohol consumption was measured using an ordinally scaled variable. The test, however, revealed a violation of that assumption, which may be expected with such a large study population [31]. As an alternative we used a multinomial modeling strategy, which ignores the ordinal structure of response variables by treating categories as nominally scaled. Alcohol consumption served as outcome with lifetime abstinence as reference category. After initial unadjusted models, a series of IQ-adjustments

Table 2 Distributions of IQ (FSIQ, PIQ, VIQ) across related factors

\begin{tabular}{|c|c|c|c|c|c|c|c|c|c|}
\hline & \multicolumn{3}{|l|}{ FSIQ } & \multicolumn{3}{|l|}{ PIQ } & \multicolumn{3}{|l|}{ VIQ } \\
\hline & Mean & SD & $p$ value & Mean & SD & $p$ value & Mean & $\mathrm{SD}$ & $p$ value \\
\hline \multicolumn{10}{|l|}{ Education } \\
\hline Not finished compulsory school & 89.66 & 17.70 & \multirow[t]{3}{*}{$\leq 0.001$} & 92.28 & 15.49 & \multirow[t]{3}{*}{$\leq 0.001$} & 90.49 & 18.26 & \multirow[t]{3}{*}{$\leq 0.001$} \\
\hline Basic education & 97.86 & 14.36 & & 98.94 & 14.76 & & 97.42 & 14.14 & \\
\hline Higher education & 107.02 & 14.05 & & 103.67 & 14.87 & & 108.20 & 13.79 & \\
\hline \multicolumn{10}{|l|}{ Disability pension } \\
\hline No & 100.28 & 14.89 & \multirow[t]{2}{*}{$\leq 0.001$} & 100.15 & 14.97 & \multirow[t]{2}{*}{$\leq 0.001$} & 100.32 & 14.87 & \multirow[t]{2}{*}{$\leq 0.001$} \\
\hline Yes & 91.84 & 15.84 & & 95.29 & 15.15 & & 90.83 & 15.57 & \\
\hline \multicolumn{10}{|l|}{ Parental migration history } \\
\hline No & 100.59 & 14.67 & \multirow[t]{2}{*}{$\leq 0.001$} & 100.30 & 14.88 & \multirow[t]{2}{*}{$\leq 0.001$} & 100.71 & 14.57 & \multirow[t]{2}{*}{$\leq 0.001$} \\
\hline Yes & 97.94 & 15.86 & & 99.03 & 15.34 & & 97.48 & 16.09 & \\
\hline \multicolumn{10}{|l|}{ Current tobacco use } \\
\hline No & 102.58 & 14.83 & \multirow[t]{2}{*}{$\leq 0.001$} & 102.16 & 14.89 & \multirow[t]{2}{*}{$\leq 0.001$} & 102.12 & 14.94 & \multirow[t]{2}{*}{$\leq 0.001$} \\
\hline Yes & 96.50 & 14.50 & & 97.07 & 14.65 & & 97.13 & 14.57 & \\
\hline \multicolumn{10}{|l|}{ Current cannabis use } \\
\hline No & 100.44 & 14.95 & \multirow[t]{2}{*}{$\leq 0.001$} & 100.56 & 14.96 & \multirow[t]{2}{*}{$\leq 0.001$} & 100.14 & 14.99 & \multirow[t]{2}{*}{$\leq 0.001$} \\
\hline Yes & 98.02 & 15.00 & & 97.43 & 14.91 & & 99.38 & 14.96 & \\
\hline \multicolumn{10}{|l|}{ Parental alcohol abuse } \\
\hline No & 100.26 & 14.90 & \multirow[t]{2}{*}{$\leq 0.001$} & 100.20 & 14.95 & \multirow[t]{2}{*}{$\leq 0.001$} & 100.22 & 14.93 & \multirow[t]{2}{*}{$\leq 0.001$} \\
\hline Yes & 96.80 & 15.49 & & 97.57 & 15.29 & & 97.11 & 15.29 & \\
\hline
\end{tabular}

Test for association of related factors with IQ is based on $t$ tests for binary variables and on ANOVA for education

$I Q$ intelligence quotient; FSIQ full-scale IQ; PIQ performance IQ; VIQ verbal IQ 
were conducted to address the main mechanisms underlying IQ-alcohol associations: (1) adjusted for the other IQ subscale, (2) adjusted for the other IQ subscale and education, (3) adjusted for the other IQ subscale and disability pension, and finally, (4) a fully adjusted model with all covariates considered. For ease of interpretation IQ scores were z-standardized prior to regression modeling; this allows the estimation of probability changes with in-/ decreasing IQ scores by 1 standard deviation, which corresponds to a rate of 15 IQ points. Odds ratio and $95 \%$ confidence intervals were calculated. All analyses were performed using STATA 12 [32].

\section{Results}

Descriptive statistics for alcohol consumption categories regarding their associations with IQ and covariates are presented in Table 1. Continuous measures such as IQ and mental health are specified as means and standard deviations $(\mathrm{M} \pm \mathrm{SD})$, and proportions and $95 \%$ confidence intervals are given for categorical variables.

Results revealed that distributions of full- and subscale IQ follow a reverse $\mathrm{j}$-shaped relationship with alcohol consumption with lowest scores in daily drinkers and highest in occasional and moderate drinkers (Table 1 and Fig. 1). Splitting up non-drinkers revealed similar scores for former drinkers and daily drinkers, whereas lifetime abstainers were similar to rare drinkers (Table 1 and Fig. 2).

All confounding factors revealed significantly distinct patterns across consumption categories. Higher education was strongly associated with moderate drinking followed by non- and occasional drinking. In the abstainer group, former drinkers had lowest rates of higher education (similar to daily drinkers) whereas lifetime abstainers had the highest rates. Lowest educational level (i.e., compulsory school not completed) was most prevalent among daily drinkers followed by non-drinkers, former drinkers

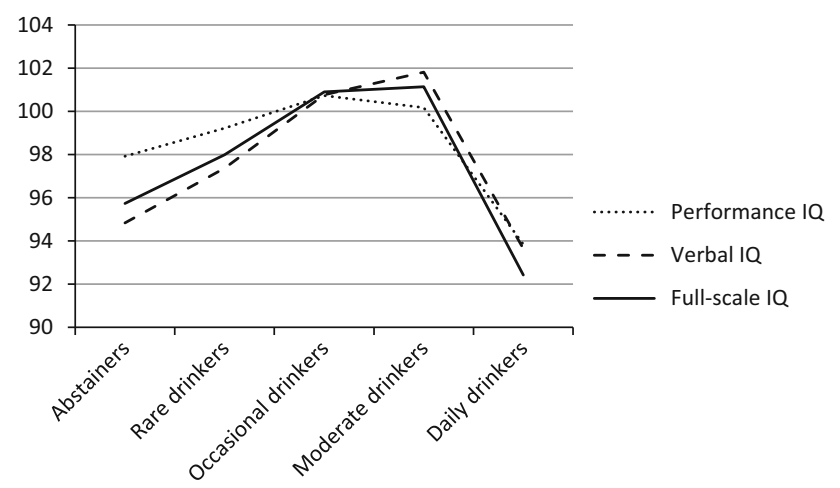

Fig. 1 IQ by drinking categories

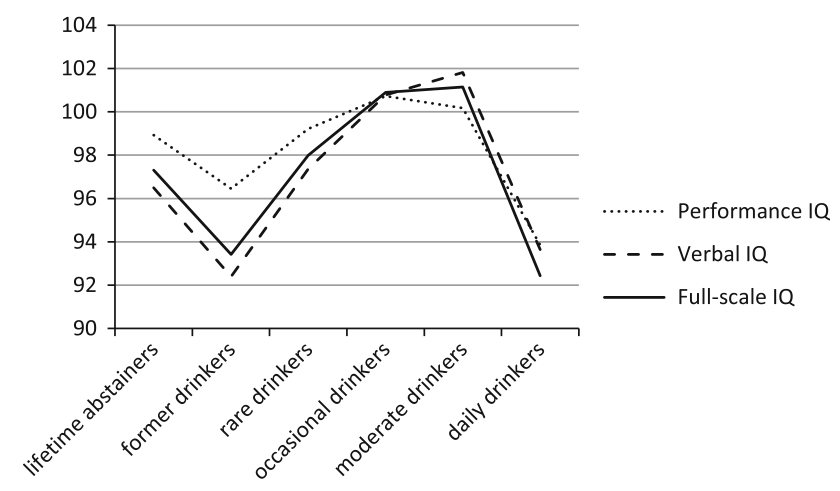

Fig. 2 IQ by drinking categories with two non-drinkers subgroups: lifetime abstainers and former drinkers

represented approximately twice as often as lifetime abstainers. Parental migration followed a j-shaped association with alcohol consumption; daily drinkers were most prevalent followed by non-drinkers, in this case higher proportions of lifetime abstainers than former drinkers. Tobacco and cannabis use was linearly related to alcohol consumption with highest prevalence in daily drinkers, and rates in former drinkers were twice as high as lifetime abstainers. Mental health status and remaining healthrelated variables, such as receipt of disability pension and parental alcohol abuse showed a j-shaped curve from nondrinkers to daily drinkers with highest values in the latter. Lifetime abstainers showed higher psychopathology than former drinkers but lower rates of disability pension and parental alcohol abuse. For more detailed information see Table 1.

Distributions of IQ scores were further examined in relation to educational levels and other covariates (see Table 2). Accordingly, lower education and other covariates are significantly associated with lower IQ. More specifically, lower education, migration history, and disability pension are associated with lower VIQ, whereas cannabis users scored lower on PIQ. Cigarette smoking and parental alcohol abuse revealed no significant differences between IQ subscales.

Table 3 shows the results of a uni-variate multinomial logistic regression model, i.e., the unadjusted probabilities of IQ (z-standardized: $1 \mathrm{SD}$ corresponds to 15 IQ points) and covariates for engaging in specific alcohol drinking behaviors (versus lifetime abstinence). Abstinence (i.e., current non-drinking) as a discrete category will not be included in subsequent analyses. According to the results, FSIQ and subscales were positively associated with occasional (FSIQ: OR 1.27; CI 95 \% 1.21-1.34, PIQ: OR 1.13; CI $95 \%$ 1.07-1.19, and VIQ: OR 1.33; CI $95 \%$ 1.27-1.40) and moderate alcohol consumption (FSIQ: OR 1.29 ; CI $95 \% 1.23-1.36$, PIQ: OR 1.09; CI $95 \%$ 1.03-1.14, and VIQ: OR 1.43; CI $95 \%$ 1.36-1.50), 
Table 3 Logistic regression models: Unadjusted probabilities of alcohol consumption categories by IQ and related factors

\begin{tabular}{|c|c|c|c|c|c|}
\hline & $\begin{array}{l}\text { Former drinkers } \\
(N=1,167 ; \\
2.36 \%) \\
\text { Unadj. OR } \\
(95 \% \mathrm{CI})\end{array}$ & $\begin{array}{l}\text { Rare drinkers }(1-5 \mathrm{x} / \text { year }) \\
(N=6,969 ; 14.09 \%) \\
\text { Unadj. OR }(95 \% \mathrm{CI})\end{array}$ & $\begin{array}{l}\text { Occasional drinkers }(1-5 \mathrm{x} / \\
\text { month })(N=25,550 ; \\
51.67 \%) \\
\text { Unadj. OR }(95 \% \mathrm{CI})\end{array}$ & $\begin{array}{l}\text { Moderate drinkers }(1-5 \mathrm{x} / \\
\text { week) }(12,595 ; 25.47 \%) \\
\text { Unadj. OR }(95 \% \mathrm{CI})\end{array}$ & $\begin{array}{l}\text { Daily drinkers } \\
(N=1,455 ; \\
2.94 \%) \\
\text { Unadj. OR } \\
(95 \% \mathrm{CI})\end{array}$ \\
\hline FSIQ & $0.78(0.72-0.84)$ & $1.05(0.99-1.10)$ & $1.27(1.21-1.34)$ & $1.29(1.23-1.36)$ & $0.72(0.68-0.78)$ \\
\hline PIQ & $0.85(0.79-0.91)$ & $1.02(0.97-1.08)$ & $1.13(1.07-1.19)$ & $1.09(1.03-1.14)$ & $0.71(0.66-0.76)$ \\
\hline VIQ & $0.77(0.72-0.83)$ & $1.06(1.00-1.11)$ & $1.33(1.27-1.40)$ & $1.43(1.36-1.50)$ & $0.83(0.79-0.89)$ \\
\hline \multicolumn{6}{|c|}{ Highest educational degree } \\
\hline No & Ref. & Ref. & Ref. & Ref. & Ref. \\
\hline Yes & $0.59(0.49-0.70)$ & $0.70(0.62-0.79)$ & $0.81(0.73-0.91)$ & $0.91(0.82-1.02)$ & $0.57(0.48-0.68)$ \\
\hline \multicolumn{6}{|c|}{ Disability pension } \\
\hline No & Ref. & Ref. & Ref. & Ref. & Ref. \\
\hline Yes & $1.27(0.87-1.85)$ & $0.68(0.51-0.91)$ & $0.57(0.43-0.74)$ & $0.59(0.45-0.79)$ & $1.33(0.94-1.90)$ \\
\hline \multicolumn{6}{|c|}{ Parental migration history } \\
\hline No & Ref. & Ref. & Ref. & Ref. & Ref. \\
\hline Yes & $0.84(0.71-0.98)$ & $0.66(0.59-0.74)$ & $0.41(0.37-0.46)$ & $0.40(0.36-0.44)$ & $0.51(0.44-0.60)$ \\
\hline \multicolumn{6}{|c|}{ Current tobacco use } \\
\hline No & Ref. & Ref. & Ref. & Ref. & Ref. \\
\hline Yes & $1.93(1.60-2.32)$ & $2.13(1.85-2.45)$ & $3.39(2.97-3.88)$ & $7.35(6.42-8.42)$ & $\begin{array}{l}21.35 \\
\quad(17.78-25.64)\end{array}$ \\
\hline \multicolumn{6}{|c|}{ Current cannabis use } \\
\hline No & Ref. & Ref. & Ref. & Ref. & Ref. \\
\hline Yes & $2.13(1.48-3.06)$ & $2.81(2.10-3.75)$ & $4.17(3.15-5.51)$ & $14.32(10.84-18.92)$ & $\begin{array}{l}52.12 \\
\quad(38.77-70.07)\end{array}$ \\
\hline \multicolumn{6}{|c|}{ Parental alcohol abuse } \\
\hline No & Ref. & Ref. & Ref. & Ref. & Ref. \\
\hline Yes & $1.41(1.04-1.90)$ & $0.87(0.69-1.10)$ & $0.84(0.68-1.04)$ & $1.33(1.07-1.65)$ & $4.30(3.36-5.50)$ \\
\hline $\begin{array}{l}\text { Mental } \\
\text { health }\end{array}$ & $0.88(0.80-0.96)$ & $0.81(0.76-0.86)$ & $0.81(0.76-0.85)$ & $1.42(1.34-1.50)$ & $2.24(2.10-2.38)$ \\
\hline
\end{tabular}

Outcome category of reference is group of "lifetime abstainers"

$I Q$ intelligence quotient; FSIQ full-scale IQ; PIQ performance IQ; VIQ verbal IQ; OR (95\%CI) Odds ratio with $95 \%$ Confidence interval

whereas former and daily drinking was linked with lower IQ (ORs 0.71 through 0.85). IQ differences between rare drinkers and lifetime abstainers were minimal and nonsignificant.

Other factors were univariately associated with alcohol consumption as follows: higher education was least likely in former $(-41 \%)$ and daily drinkers $(-43 \%)$, followed by rare $(-30 \%)$ and occasional drinkers $(-19 \%)$. With respect to education moderate drinkers did not differ significantly from lifetime abstainers. Disability pension was less likely in rare to moderate drinkers $(-43 \%$ through $-32 \%$ ) former and daily drinkers were similar to lifetime abstainers. Parental migration history was more likely in lifetime abstainers than any other category, with lowest probabilities in occasional $(-59 \%)$ and moderate drinkers $(-60 \%)$ and highest in former drinkers $(-16 \%)$. Similarly, smoking and cannabis use was least likely in lifetime abstainers, with increasing probabilities from former (factor smoking $_{1.93 \text {; factor }}$ cannabis 2.13 ) to daily drinking (factor $_{\text {smoking }}$ 21.35; factor cannabis $_{\text {52.12). Presence of }}$ parental alcohol disorders was more likely in former (factor 1.41), moderate (factor 1.33), and daily drinkers (factor 4.3) compared with lifetime drinkers while no differences were found for rare and occasional drinkers. Mental health problems were negatively associated with former (OR 0.88; CI $95 \% 0.80-0.96$ ) and occasional drinking (OR 0.81 ; CI $95 \%$ 0.76-0.85) but positively with moderate (OR 1.42; CI95 \% 1.34-1.50) and daily drinking (OR 2.24; CI $95 \%$ 2.10-2.38).

Finally, adjusted models for potential confounders were calculated. Adjusting for education increased the association between FSIQ and rare-to-moderate consumption but decreased the negative association with former and daily drinking (Table 4). These associations were stronger when all other factors were adjusted for. The association with daily drinking, however, disappeared. Adjusting for 


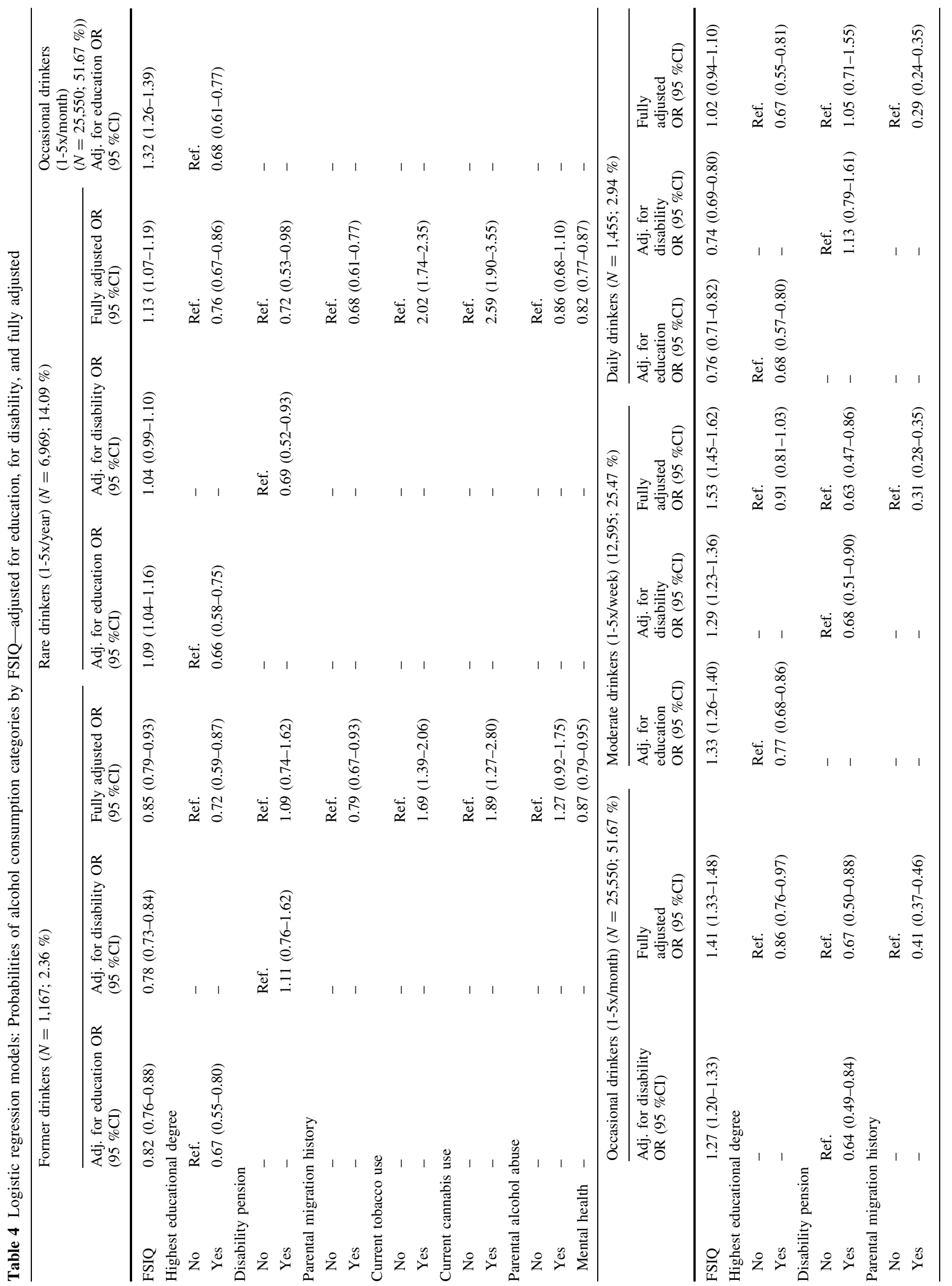




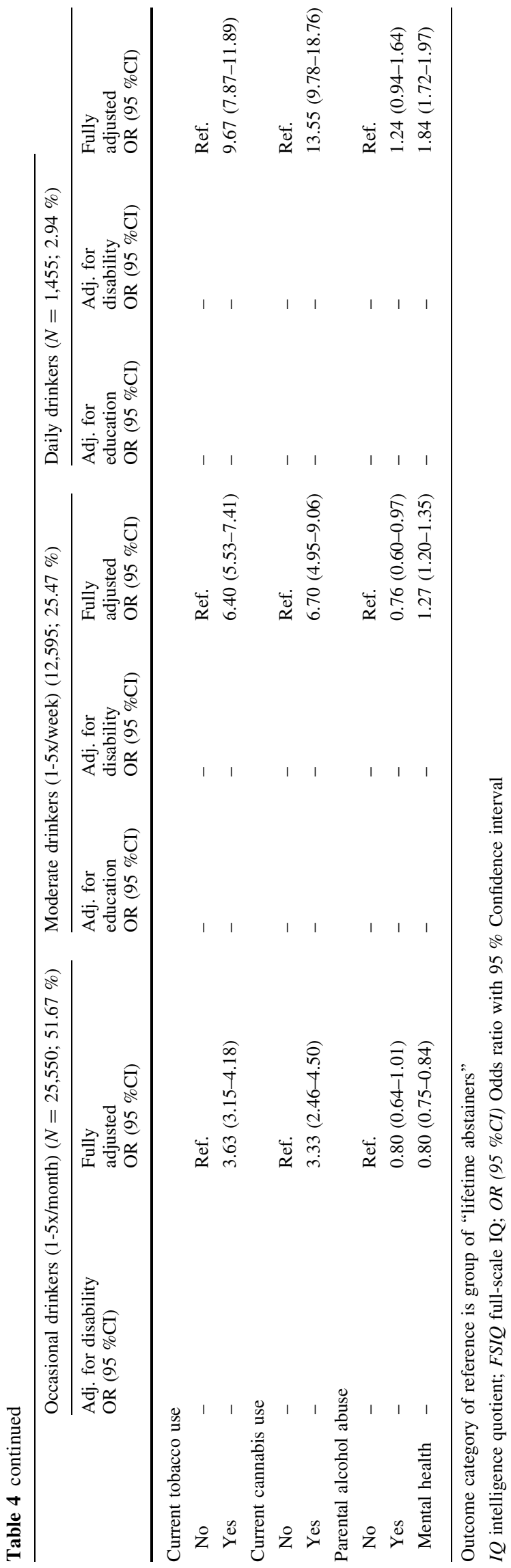

disability pension only revealed no differences to unadjusted models.

Inclusion of both IQ subscales in one model fully eliminated the PIQ-alcohol association apart from daily drinking; here a bi-variate association remained (Table 5). In contrast, the VIQ-alcohol association remained at unadjusted association levels, except in daily drinkers, where significance was lost. Adjusting only for education revealed no change in estimates for PIQ but slightly increased odds ratios for VIQ, which, however, remained non-significant for daily drinking. Adjusting for disability pension alone revealed similar estimates to unadjusted associations apart from VIQ where the significant association with rare drinking disappeared. After full adjustment, associations of PIQ with occasional and moderate drinking reached significance for a positive relationship but lost significance for daily drinking. After full adjustment, associations between VIQ and drinking categories revealed highest relationships including a positive link with daily drinking.

\section{Discussion}

To our knowledge this is the first comprehensive survey exploring the relationship between IQ data and alcohol consumption in a large sample of young males. We had the benefit of a representative and generally healthy young sample, with cognitive abilities considered unlikely to be affected by earlier drinking habits. In this age group IQ is presumed to be relatively stable and likely to reflect earlier cognitive abilities-irrespective of environmental influences [33,34]. Any cognitive deficits may therefore be assumed to be pre-existent [18]. Multiple measures of IQ allowed us to examine the possible differential effects of IQ on the frequency of alcohol consumption. Our analyses were well controlled; suspected malingerers and participants with organic mental diseases or mental deficiency were excluded. Furthermore, a range of variables, which might confound the IQ-alcohol association, was taken into account for control purposes.

We hypothesized poorer IQ to be associated with former and daily drinking while moderate drinkers were expected to show higher IQ scores. This hypothesis was only partially supported. Although initially confirmed by bi-variate results this association was partly explained by confounders. We found that education was a suppressor within the relationship between rare-to-moderate drinking, whereas in former and daily drinkers it was mediated instead. These differences arise from higher education rates in moderate drinkers, and education, in turn, was highly correlated with IQ in bi-variate associations. This corresponds to a metaanalysis exploring specific characteristics of different 
drinking groups, where both former and heavy drinkers were likely to be less educated than light-to-moderate drinkers [35]. Disability pension did not confound this relationship but was negatively linked to rare to moderate consumption, which is also in line with earlier research results [36]. Finally, all considered confounders in one model further increased the suppression of the IQ-alcohol association in rare-to-moderate drinkers as well as the mediation in former and daily drinking (full mediation in the latter). However, differential subscale results seemed to lead to the attenuation of FSIQ in daily drinking: whereas PIQ was initially negatively linked, this association was attenuated after full adjustment with a reversed effect for VIQ, i.e., the non-existent VIQ association became positive.

This provides evidence for a shift in cognitive performance between "normal level"-drinkers and abstainers [4, 18, 37-40]. Thus, IQ may be a strong predictor of later life habits including drinking behavior-generally revealing healthier patterns for those with higher IQ. For example, a previous study found pre-existing higher IQ independently supported continuous moderate drinking and, therefore, reducing the risk for later alcohol-related problems [41]. Although studies of older populations with positive longterm effects of moderate consumption on cognitive function suggested a reverse causality [42], it is possible that the link between IQ and drinking behavior is shaped much earlier, i.e., prior to the onset of drinking [11, 43].

Furthermore, our data provided strong evidence for lower IQ in former drinkers together with significantly more psychosocial risk factors when compared with lifetime abstainers. This suggests that it is not non-drinking per se, which is linked to cognitive deficits, rather other important differences, which are in turn linked to cognitive variables, such as IQ [6, 7]. For example, former drinkers are more likely to have health-related or psychosocial problems, that are associated with lower IQ, which led them to cease drinking [44-47]. This explanation, however, may not apply to our young sample. Nevertheless, significant differences between lifetime abstainers and former drinkers might support this view, e.g., former drinkers reported higher tobacco and cannabis use than lifetime abstainers and more often received disability pension (cf. daily drinkers). Furthermore, lifetime abstainers had lower proportions of parental alcohol abuse than the sample average and were higher educated than other groups. Finally, family migration background was most specific for non-drinkers; more than a third of this group had at least one non-Swiss parent, predominantly in the lifetime abstention group. Abstinence is often culturally determined, which may be partly attributable to religion, although this effect is generally attenuated in second-generation immigrants [48, 49]. In western societies, such as
Switzerland, moderate consumption belongs to norm-oriented behavior, whereas both heavy and non-drinking are the exception rather than the rule.

Interestingly, a negative association between IQ and higher consumption was not confirmed by our data. Mortensen et al. [15] supposed that an association between IQ and high consumption in this age group might indeed exist, which, however, does not become apparent until higher levels of intake at a special occasion. Assuming that our daily drinking group consists of both a majority of moderate-daily and a smaller proportion of heavy-daily drinkers might explain the partially positive association with IQ. This, however, is consistent with a recent finding from a large longitudinal study exploring the link between IQ and the risk of heavy drinking over the lifespan (Wilmoth, unpublished). In this study an initially positive association was found in males with similar ages as our sample; this relationship, however, became negative with increasing age. On the other hand, under-reporting, especially in cases of heavy drinkers, may also have led to a reduction of such effects. Although self-reports of substance use are potentially biased by social desirability evidence exists that self-reports of substance use, particularly in conscripts, are sufficiently reliable to be used in epidemiological studies [36].

Summing up our data provide some evidence that a causal pathway between IQ and drinking behavior might exist, which is shaped by a complex framework of factors including both genetic and shared environmental selection processes [1]. IQ is assumed to be associated with a tendency for specific socio-demographic features which may affect lifestyle orientation including drinking habits [41]. Given the strong associations between IQ and all covariates considered in this study-for example education-these factors were substantial enough to explain the IQ-alcohol relationship in terms of confounding.

The conclusions drawn from this study should be understood in the context of its strengths and limitations. A major strength of this study is the large, representative sample of young males providing information on alcohol consumption frequency and IQ data from an entire 2-yearsample of Swiss conscripts. As our findings are based on conscription data, i.e., the participation in our study was mandatory; a possible selection bias was minimized. Strengths further included our approach separating former drinkers and lifetime abstainers. Other studies have pointed out the importance of this distinction due to suspected differences, including cognitive abilities, between these groups. Finally, although the IQ test administered to the Swiss conscripts was not a well-established psychometric test it has been validated and standardized against internationally recognized measures [27]. The data benefit from the large population base, which allowed calculation of standard IQ scores. Moreover, dividing IQ tests into sub- 


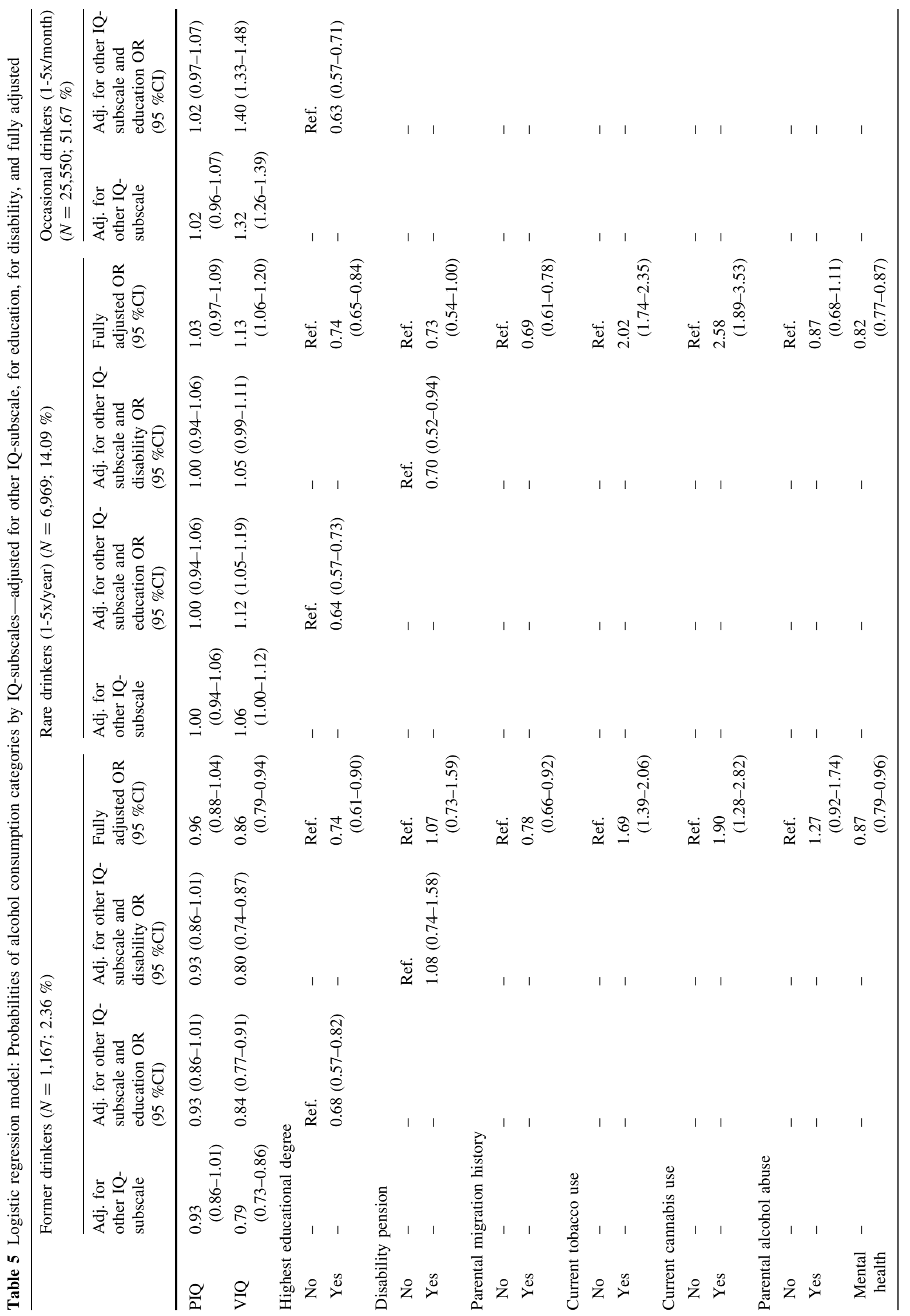




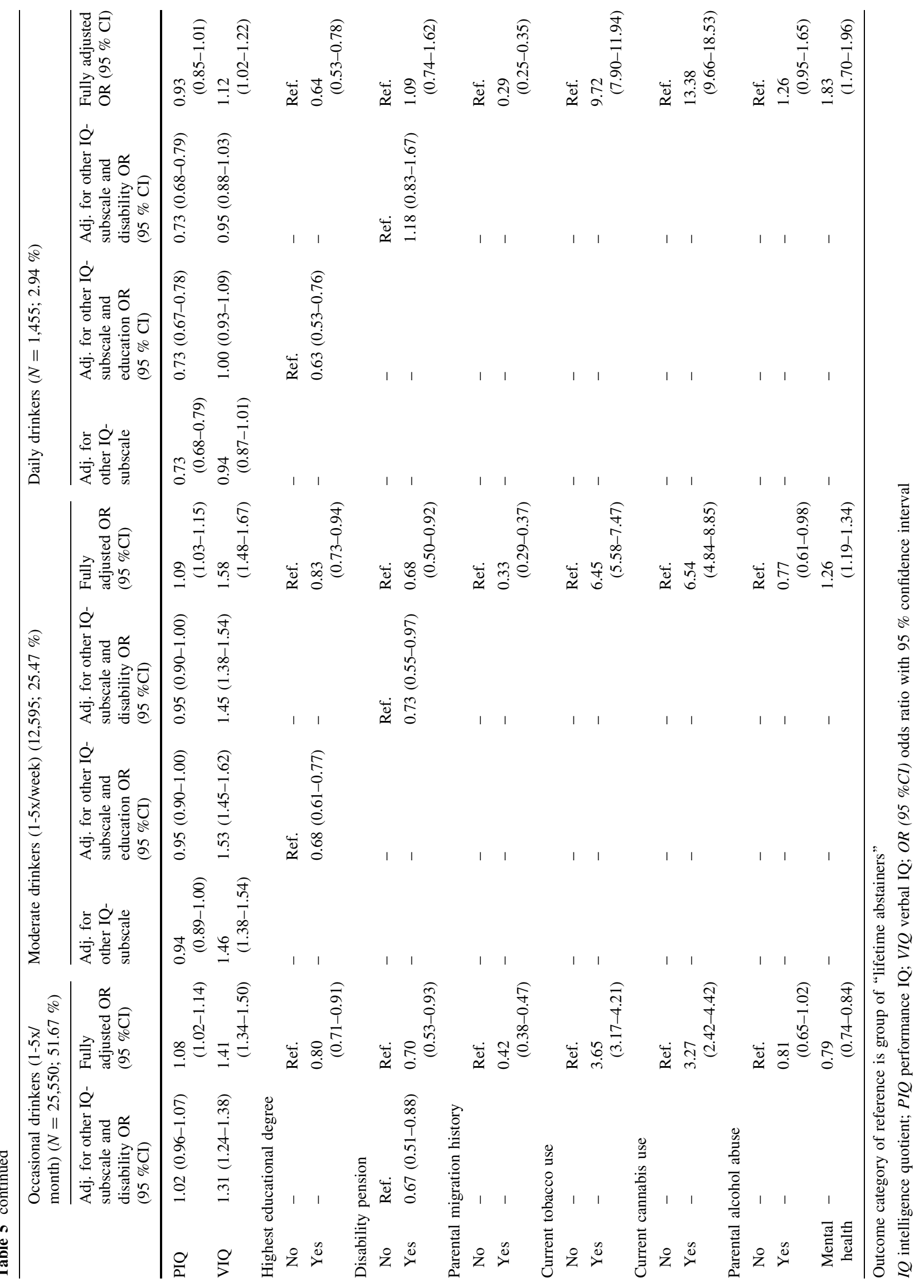


dimensions of verbal and performance tasks underlined interesting trends.

An inherent disadvantage of our data is that our results may not generalize to other age or cultural groups with different drinking habits. Similarly, our findings may not be applicable to females since they tend to drink lower quantities of alcohol than males and changes in drinking habits over time are lower [50, 51]. However, despite drinking lower quantities of alcohol females were found to have comparable levels of at-risk drinking as males since they reach critical levels of intoxication more quickly [52]. Further limitations of this study include a lack of quantitative and chronological information on alcohol consumption including duration of current drinking patterns, changes in drinking behavior and reasons for doing so, reasons for not drinking in lifetime abstainers, and the average amount of alcohol consumed on "drinking days". Moreover, our method of splitting up non-drinkers into lifetime abstainers and former drinkers may result in participants who tried alcohol only once or twice in their lives being categorized as former drinkers. Lack of precise information impeded more accurate interpretation of the data. Similarly, it might be problematic to consider daily drinking as a reliable indicator of high consumption. In conclusion, it is unlikely we found real problem drinkers in this age group; their "high" consumption may occur on isolated "high-intake" occasions and many will decrease their consumption in later life [53]. A final limitation of the present study is its cross-sectional design. Since all information was recorded within 3 days of conscription examination relating IQ data to alcohol consumption may raise questions of causality. On the other hand a study sample of this young age is unlikely to show marked effects of alcohol consumption on IQ at this stage.

Acknowledgments The authors would like to thank Major Dr. Franz Frey, Head of the Medical Services of the Swiss Armed Forces, for allowing access to the data and for his valued assistance and support. Additional thanks to Lorna McBroom for proofreading the final version of the manuscript.

Conflict of interests The authors declare that they have no conflict of interests.

\section{References}

1. Johnson W, Hicks BM, McGue M, Iacono WG (2009) How intelligence and education contribute to substance use: hints from the Minnesota Twin Family Study. Intelligence 37(6):613-624. doi:10.1016/j.intell.2008.12.003

2. Fan X, O'Donnell A, Singh SP, Pungan R, Perlmuter LC (2008) Light to moderate alcohol drinking is associated with higher cognitive function in males with type 2 diabetes. Exp Aging Res 34(2):126-137. doi:10.1080/03610730701876953
3. Stampfer MJ, Kang JH, Chen J, Cherry R, Grodstein F (2005) Effects of moderate alcohol consumption on cognitive function in women. N Engl J Med 352(3):245-253. doi:10.1056/NEJMoa041152

4. Elias PK, Elias MF, D'Agostino RB, Silbershatz H, Wolf PA (1999) Alcohol consumption and cognitive performance in the Framingham Heart Study. Am J Epidemiol 150(6):580-589

5. Arntzen KA, Schirmer H, Wilsgaard T, Mathiesen EB (2010) Moderate wine consumption is associated with better cognitive test results: a 7 year follow up of 5033 subjects in the Tromso study. Acta Neurol Scand Suppl 190:23-29. doi:10.1111/j.16000404.2010.01371.x

6. Andreasson S (1998) Alcohol and J-shaped curves. Alcohol Clin Exp Res 22(7 Suppl):359S-364S

7. Leifman H, Kuhlhorn E, Allebeck P, Andreasson S, Romelsjo A (1995) Abstinence in late adolescence-antecedents to and covariates of a sober lifestyle and its consequences. Soc Sci Med 41 (1):113-121. pii 0277953694002988

8. Anttila T, Helkala EL, Viitanen M, Kareholt I, Fratiglioni L, Winblad B, Soininen H, Tuomilehto J, Nissinen A, Kivipelto M (2004) Alcohol drinking in middle age and subsequent risk of mild cognitive impairment and dementia in old age: a prospective population based study. BMJ 329(7465):539. doi:10.1136/bmj.38181.418958.BE

9. Neafsey EJ, Collins MA (2011) Moderate alcohol consumption and cognitive risk. Neuropsychiatr Dis Treat 7:465-484. doi: 10.2147/NDT.S23159

10. Green A, Garrick T, Sheedy D, Blake H, Shores EA, Harper C (2010) The effect of moderate to heavy alcohol consumption on neuropsychological performance as measured by the repeatable battery for the assessment of neuropsychological status. Alcohol Clin Exp Res 34(3):443-450. doi:10.1111/j.1530-0277.2009.01108.x

11. Corley J, Jia X, Brett CE, Gow AJ, Starr JM, Kyle JA, McNeill G, Deary IJ (2011) Alcohol intake and cognitive abilities in old age: the Lothian Birth Cohort 1936 Study. Neuropsychology 25(2):166-175. doi:10.1037/a0021571

12. Schinka JA, Vanderploeg RD, Rogish M, Ordorica PI (2002) Effects of alcohol and cigarette use on cognition in middle-aged adults. J Int Neuropsychol Soc 8(5):683-690

13. Kanazawa S, Hellberg JEEU (2010) Intelligence and substance use. Rev Gen Psychol 14(4):382-396. doi:10.1037/A0021526

14. Batty GD, Deary IJ, Macintyre S (2006) Childhood IQ and life course socioeconomic position in relation to alcohol induced hangovers in adulthood: the Aberdeen children of the $1950 \mathrm{~s}$ study. J Epidemiol Community Health 60(10):872-874. doi:10.1136/ jech.2005.045039

15. Mortensen LH, Sorensen TI, Gronbaek M (2005) Intelligence in relation to later beverage preference and alcohol intake. Addiction 100(10):1445-1452. doi:10.1111/j.1360-0443.2005.01229.x

16. Goretti B, Portaccio E, Zipoli V, Hakiki B, Siracusa G, Sorbi S, Amato MP (2010) Impact of cognitive impairment on coping strategies in multiple sclerosis. Clin Neurol Neurosurg 112 (2):127-130. doi:10.1016/j.clineuro.2009.10.019

17. Goretti B, Portaccio E, Zipoli V, Razzolini L, Amato MP (2010) Coping strategies, cognitive impairment, psychological variables and their relationship with quality of life in multiple sclerosis. Neurol Sci 31(Suppl 2):S227-S230. doi:10.1007/s10072-010-0372-8

18. Mortensen EL, Jensen HH, Sanders SA, Reinisch JM (2006) Associations between volume of alcohol consumption and social status, intelligence, and personality in a sample of young adult Danes. Scand J Psychol 47(5):387-398. doi:10.1111/j.14679450.2006.00520.x

19. Huth C, Siegert N, Meisinger C, Konig J, Kaab S, Wichmann HE, Doring A (2007) Individuals with very low alcohol consumption: a heterogeneous group. J Stud Alcohol Drugs 68(1):6-10

20. Fonnebo V (1992) Mortality in Norwegian Seventh-Day Adventists 1962-1986. J Clin Epidemiol 45(2):157-167 0895-4356 (92)90008-B [pii] 
21. Kjaerheim K, Andersen A, Helseth A (1993) Alcohol abstainers: a low-risk group for cancer-a cohort study of Norwegian teetotalers. Cancer Epidemiol Biomarkers Prev 2(2):93-97

22. Meyers AR, Hingson R, Mucatel M, Heeren T, Goldman E (1985) The social epidemiology of alcohol use by urban older adults. Int J Aging Hum Dev 21(1):49-59

23. Graham K (1998) Alcohol abstention among older adults: reasons for abstaining and characteristics of abstainers. Addict Res 6(6): 473-487

24. Saarni SI, Joutsenniemi K, Koskinen S, Suvisaari J, Pirkola S, Sintonen H, Poikolainen K, Lonnqvist J (2008) Alcohol consumption, abstaining, health utility, and quality of life-a general population survey in Finland. Alcohol Alcohol 43(3):376-386. doi:10.1093/alcalc/agn003

25. Anstey KJ, Windsor TD, Rodgers B, Jorm AF, Christensen H (2005) Lower cognitive test scores observed in alcohol abstainers are associated with demographic, personality, and biological factors: the PATH Through Life Project. Addiction 100(9):12911301. doi:10.1111/j.1360-0443.2005.01159.x

26. Foppa N, Roduner K, Oberwiler A (1997) Die Konstruktvalidität des Test 95. Abteilung Angewandte Psychologie der Universität, Zürich

27. Huber R (1999) Test 95. Von der Planung bis zur Einführung eines Kurzintelligenztests, Lang

28. Althoff K, Jäger AO (1983) Der WILDE-Intelligenz-Test-Ein Strukturdiagnostikum. Hogrefe, Göttingen

29. Ekstrom R, French JW, Harman HH (1976) Manual for KIT of factor-referenced cognitive tests. Educational Testing Service, Princton

30. Derogatis LR, Lipman RS, Covi L (1973) SCL-90: an outpatient psychiatric rating scale-preliminary report. Psychopharmacol Bull 9(1):13-28

31. Brant R (1990) Assessing proportionality in the proportional odds model for ordinal logistic regression. Biometrics 46(4):1171-1178

32. StataCorp (2011) Stata Statistical Software. Release 12 edn. StataCorp, College Station, TX

33. Bartels M, Rietveld MJ, Van Baal GC, Boomsma DI (2002) Genetic and environmental influences on the development of intelligence. Behav Genet 32(4):237-249

34. Petrill SA, Lipton PA, Hewitt JK, Plomin R, Cherny SS, Corley R, DeFries JC (2004) Genetic and environmental contributions to general cognitive ability through the first 16 years of life. Dev Psychol 40(5):805-812. doi:10.1037/0012-1649.40.5.805

35. Fillmore KM, Golding JM, Graves KL, Kniep S, Leino EV, Romelsjo A, Shoemaker C, Ager CR, Allebeck P, Ferrer HP (1998) Alcohol consumption and mortality. I. Characteristics of drinking groups. Addiction 93(2):183-203

36. Upmark M, Hemmingsson T, Romelsjo A, Lundberg I, Allebeck P (1997) Predictors of disability pension among young men. The role of alcohol and psychosocial factors. Eur J Public Health 7(1):20-28

37. Hendrie HC, Gao S, Hall KS, Hui SL, Unverzagt FW (1996) The relationship between alcohol consumption, cognitive performance, and daily functioning in an urban sample of older black Americans. J Am Geriatr Soc 44(10):1158-1165

38. Marmot MG, Rose G, Shipley MJ, Thomas BJ (1981) Alcohol and mortality: a U-shaped curve. Lancet 1(8220 Pt 1):580-583

39. Holahan CJ, Schutte KK, Brennan PL, Holahan CK, Moos BS, Moos RH (2010) Late-life alcohol consumption and 20-year mortality. Alcohol Clin Exp Res 34(11):1961-1971. doi:10.1111/ j.1530-0277.2010.01286.x
40. Baum-Baicker C (1985) The psychological benefits of moderate alcohol consumption: a review of the literature. Drug Alcohol Depend 15(4):305-322

41. Molander RC, Yonker JA, Krahn DD (2010) Age-related changes in drinking patterns from mid- to older age: results from the Wisconsin longitudinal study. Alcohol Clin Exp Res 34(7): 1182-1192. doi:10.1111/j.1530-0277.2010.01195.x

42. Kim JW, Lee DY, Lee BC, Jung MH, Kim H, Choi YS, Choi IG (2012) Alcohol and cognition in the elderly: a review. Psychiatry Investig 9(1):8-16. doi:10.4306/pi.2012.9.1.8

43. Kubicka L, Matejcek Z, Dytrych Z, Roth Z (2001) IQ and personality traits assessed in childhood as predictors of drinking and smoking behaviour in middle-aged adults: a 24-year follow-up study. Addiction 96(11):1615-1628. doi:10.1080/096521401 20080741

44. Latvala A, Tuulio-Henriksson A, Dick DM, Vuoksimaa E, Viken RJ, Suvisaari J, Kaprio J, Rose RJ (2011) Genetic origins of the association between verbal ability and alcohol dependence symptoms in young adulthood. Psychol Med 41(3):641-651. doi: 10.1017/S0033291710001194

45. Hanson KL, Cummins K, Tapert SF, Brown SA (2011) Changes in neuropsychological functioning over 10 years following adolescent substance abuse treatment. Psychol Addict Behav 25(1):127-142. doi:10.1037/a0022350

46. Ganguli M, Vander Bilt J, Saxton JA, Shen C, Dodge HH (2005) Alcohol consumption and cognitive function in late life: a longitudinal community study. Neurology 65(8):1210-1217. doi: 10.1212/01.wnl.0000180520.35181.24

47. Graham K, Massak A, Demers A, Rehm J (2007) Does the association between alcohol consumption and depression depend on how they are measured? Alcohol Clin Exp Res 31(1):78-88. doi:10.1111/j.1530-0277.2006.00274.x

48. Amundsen EJ, Rossow I, Skurtveit S (2005) Drinking pattern among adolescents with immigrant and Norwegian backgrounds: a two-way influence? Addiction 100(10):1453-1463. doi: 10.1111/j.1360-0443.2005.01177.x

49. Bernards S, Graham K, Kuendig H, Hettige S, Obot I (2009) 'I have no interest in drinking': a cross-national comparison of reasons why men and women abstain from alcohol use. Addiction 104(10):1658-1668. doi:10.1111/j.1360-0443.2009.02667.x

50. Chen P, Jacobson KC (2012) Developmental trajectories of substance use from early adolescence to young adulthood: gender and racial/ethnic differences. J Adolesc Health 50(2):154-163. doi:10.1016/j.jadohealth.2011.05.013

51. Silveira CM, Siu ER, Wang YP, Viana MC, Andrade AG, Andrade LH (2012) Gender differences in drinking patterns and alcoholrelated problems in a community sample in Sao Paulo, Brazil. Clinics (Sao Paulo) 67 (3):205-212. pii: S1807-59322012000 300001

52. Trillo AD, Merchant RC, Baird JR, Liu T, Nirenberg TD (2012) Sex differences in alcohol misuse and estimated blood alcohol concentrations among emergency department patients: implications for brief interventions. Acad Emerg Med 19(8):924-933. doi:10.1111/j.1553-2712.2012.01408.x

53. Upmark M, Lundberg I, Sadigh J, Allebeck P, Bigert C (1999) Psychosocial characteristics in young men as predictors of early disability pension with a psychiatric diagnosis. Soc Psychiatry Psychiatr Epidemiol 34(10):533-540. pii: 90340533.127 